\title{
Detection and Genomic Characterization of Senecavirus from Indian Pigs
}

Sushila Maan, Kanisht Batra, Deepika Chaudhary, Monika Punia', Vijay Kadian, Vinay G. Joshi, Aman Kumar

10.18805/IJAR.B-4722

\begin{abstract}
Background: Senecavirus A (SVA), is a positive sense small non-enveloped RNA virus which belongs to Picornaviridae family and is responsible for porcine vesicular disease. The disease has been reported in many countries since late 2014,2015 and 2016 like USA, Canada, Brazil, China and Thailand.

Methods: In this study, the metagenomic study was performed on faecal samples of pigs/piglets suffering from diarrhea in Haryana, India with the help of next generation sequencing. The cDNA library was prepared from the faecal samples and run on the Illumina MiSeq instrument followed by identification and genomic characterization.

Result: This study revealed the presence of SVA in the samples. The characterization of complete genome sequence of this strain showed complete nucleotide identity (100\%) with SVA genomes reported from Canada, however, the polyprotein shares $98-99 \%$ amino acid sequence similarity with the genomes currently available in the GenBank. To the best of our knowledge this is the first report of SVA infection in pigs/piglets of Haryana, India. It demonstrates that an active and urgent surveillance of the swine population is required in the region. Additionally, the veterinarians must pay immediate attention to this vesicular disease and adopt preventive measures for its control.
\end{abstract}

Key words: Next generation sequencing (NGS), Pigs, Senecavirus, Whole genome.

\section{INTRODUCTION}

Seneca Valley virus A (SVA) is a single-stranded, positivesense non-enveloped, virus belonging to Genus Senecavirus, family Picornaviridae (Venkataraman et al., 2008). This Picornaviridae family contains many viruses that are responsible for disease in several animals and humans like enterovirus $A$, rhinovirus- $A,-B$ and $-C$ and Foot-and mouth disease virus (FMDV) (Racaniello, 2013). This is closely related to the genus Cardiovirus, including cardiovirus A (encephalomyocarditis virus, EMCV) and -B (Theiler's murine encephalomyelitis virus, TMEV) (ICTV, 2015), which are responsible for infection in wide range of vertebrate species, including humans, pigs and mice (Carocci and Bakkali-Kassimi, 2012; Hales et al., 2008). The characteristics lesion in this disease includes lameness, lethargy, vesicles on the snout, oral mucosa and coronary bands (Canning et al., 2016). The clinical lesions of this disease are need to be differentially diagnosed with other vesicular diseases of swine including FMDV, vesicular stomatitis (VS), swine vesicular disease (SVD) and vesicular exanthema (VE) of swine (Pasma et al., 2008). Therefore, this disease needs development of rapid diagnostic methods for differentiating from other similar vesicular disease of pigs. The currently available diagnosis of SVA is mainly based on the detection of clinical lesions supplemented with nucleic acid based diagnosis. The conventional RT-PCR targeting VP1 or the 5' untranslated region (5' UTR) I (Joshi et al., 2016) and quantitative RT-PCR (qRT-PCR) based on conserved genomic region within the VP1 gene of the SVA (Dall et al., 2017) have been used. However, due to variation
College of Veterinary Sciences, Lala Lajpat Rai University of Veterinary and Animal Sciences, Hisar-125 001, Haryana, India. 'Department of Biotechnology, Ch. Devi Lal University, Sirsa-125 055, Haryana, India.

Corresponding Author: Sushila Maan, Department of Animal Biotechnology, College of Veterinary Sciences, Lala Lajpat Rai University of Veterinary and Animal Sciences, Hisar-125 001, Haryana, India. Email: sushilamaan105@gmail.com

How to cite this article: Maan, S., Batra, K., Chaudhary, D., Punia, M., Kadian, V., Joshi, V.G. and Kumar, A. (2021). Detection and Genomic Characterization of Senecavirus from Indian Pigs. Indian Journal of Animal Research. DOI: 10.18805/IJAR.B-4722.

Submitted: 14-07-2021 Accepted: 12-10-2021 Online: 19-11-2021

in progression of senecavirus along with change in the viral shedding and/or load in biological samples, the detection of SVA with molecular techniques is inconsistent (GimenezLirola et al., 2016). Therefore, it needs a variety of specimens including serum, tonsils, faeces and oral and vesicular fluids, for screening by molecular assays. The next-generation sequencing (NGS) technology in addition to PCR has been well used for viral diagnosis. The epidemiologic surveillance based on NGS technology has the potential to help identify novel pathogens and to clarify the global distribution of these pathogens. In the present study, metagenomics based nextgeneration sequencing was performed to characterize the virus present in diarrheic specimens from a pig farm of Haryana state. 


\section{MATERIALS AND METHODS}

For molecular study, a total of 59 diarrheic swab samples were collected from two different organised pig farms (Latitude and longitude coordinates: 28.8, 76.6) suffering from diarrhea and other skin lesions and with nasal and lacrymal discharges (Fig 1). These samples were preserved in sterile PBS $(1 \mathrm{ml})$ at $-20^{\circ} \mathrm{C}$. Out of 59 samples, only six samples having high scoring based on symptoms from diarrheic pigs were processed for RNA extraction and for library preparation for Next Generation sequencing (NGS) study. The details of six samples included in this study are given in Table 1.

\section{Extraction of RNA}

The samples $(n=6)$ were used for extraction of viral RNA using combination of Trizol reagents and viral RNeasy plus mini kit (Qiagen). Samples after trizol extraction were treated with DNA elimination buffer for removal of DNA. This extracted RNA was quantified using a Qubit ${ }^{\circledR} 2.0$ Fluorometer (Invitrogen).

\section{Library preparation and whole genome sequencing}

The cDNA library was prepared using Nextera XT DNA Library Prep Kit using the standard protocol. The purity and integrity of RNA as well as cDNA library prepared was

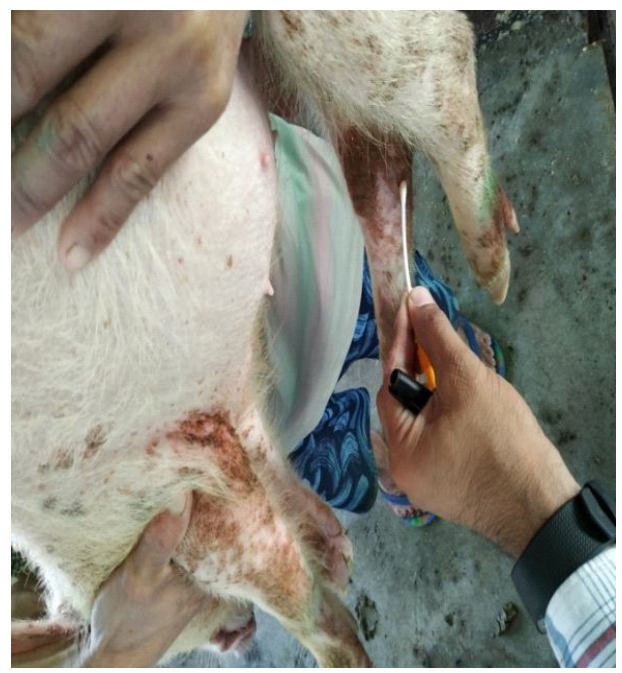

a measured using an AATI Fragment Analyser (USA). A 300 cycles, 150 paired end sequencing protocol was used for sequencing on an Illumina MiSeq instrument as recommended by the manufacturer. The sequencing reads were assembled using the de novo approach by using the pipeline developed at the University of Minnesota.

\section{Sequence and phylogenetic analysis}

The contigs obtained from NGS data were analysed using NCBI BLAST online software tool available on the internet (http://www.ncbi.nlm.nih.gov/BLAST/). The sequences were aligned using CLUSTAL W software and bootstrap probabilities were calculated with 1,000 replicates. MEGA 6 software was used to construct phylogenetic tree to show genetic relatedness of SVA from different origins. Neighbourhood joining (NJ) phylogenetic trees was constructed using published nucleotide sequences of SVA virus obtained from GenBank.

These moleculer studies were carried out at the Department of Animal Biotechnology, COVS, LUVAS, Hisar in the year 2020 .

\section{RESULTS AND DISCUSSION}

The increased incidences of many infectious diseases in swine that are either caused by new or existing strains are

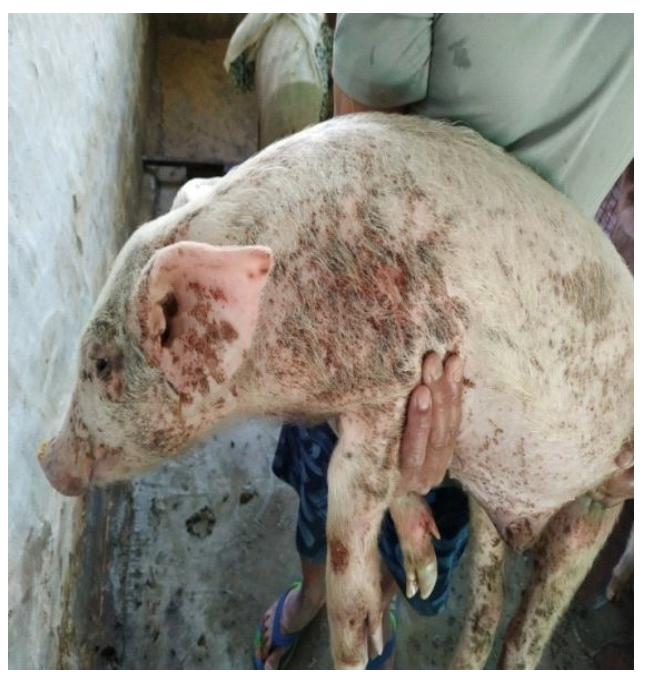

b

Fig 1a,b: Clinical symptoms in pigs affected with Senecavirus A.

Table 1: Details of samples used for next generation sequencing analysis.

\begin{tabular}{lcllc}
\hline Sample ID & Sex & Age & Housing & Clinical scoring \\
\hline IND/2019/01-SVA & Male & 2 months & Organized farm intensive pucca floor rearing & +++ \\
IND/2019/02-SVA & Female & 2 months & Organized farm intensive pucca floor rearing & ++ \\
IND/2019/03-SVA & Female & 2 months & Organized farm intensive pucca floor rearing & ++ \\
IND/2019/04-SVA & Male & 2 months & Organized farm intensive pucca floor rearing & + \\
IND/2019/05-SVA & Female & 2.5 years & Organized farm intensive pucca floor rearing & ++ \\
IND/2019/06-SVA & Male & 2.5 years & Organized farm intensive pucca floor rearing & ++ \\
\hline
\end{tabular}

The samples were scored based on clinical symptoms +++: Pigs suffering from extreme watery diarrhea with respiratory symptoms, ++ : Pigs suffering from loose diarrhea at intervals, +: Pigs suffering from milder form of diarrhea with no other symptoms, 0 : Pigs showing no signs and symptoms. 
result of long-term changes in the pathogens epidemiology (Woolhouse, 2002). There are number of emerging and reemerging infectious diseases of swine, which have increased exponentially from last 20 years (Segale and Mateu, 2012; Rout et al., 2018; Pegu et al., 2017a). This includes the emergence of porcine reproductive and respiratory syndrome (PRRS), porcine circovirus type 2 systemic disease (PCV2-SD) and porcine epidemic diarrhea (PED) in North America, India and Europe (Pegu et al., 2017b). These numbers might increase in the near future because of the pattern of discovery of novel emerging pathogens is high (7.5 per year from 2001 to 2010). The SVA virus has already known for oncolytic potential in human therapies but its association with swine disease was not found in India till now.

In the present study, viral RNA was extracted from six faecal samples as described in material and methods. The concentration of RNA was observed to be $10-50 \mathrm{ng} / \mu \mathrm{l}$ in these samples. For preparation of genome library $\sim 10 \mathrm{ng} / \mu \mathrm{l}$ concentration of RNA were used. Libraries were generated from these samples. The next generation sequencing using illumina platform resulted generation of nearly $11 \mathrm{~GB}$ of data from six samples. Analysis of the NGS data helped us in digging out major reads containing whole genome of SVA virus from one of the diarrheic samples. Phylogenetic analysis of whole genome of SVA virus was conducted by comparing genome sequence of the Indian SVA virus with the other worldwide circulating strains (available on GenBank) (Fig 2). The whole genome sequencing results revealed that Indian SVA consisted of 6,546 nucleotides (nt), of coding sequences, having an open reading frame encoding a polyprotein with 2,181 amino acids (aa). The coding sequence of Indian Senecavirus A 2019 strain (IND/ 2019/01-SVA) has been deposited in GenBank with Accession No. MZ395819. Coding sequence of SVA virus was aligned with other sequences of Senecavirus present in the GenBank. SVA infection is responsible for neonatal mortality nearly 30-70\% (Leme et al., 2015 and WU et al., 2016). Currently, the SVA outbreaks have been reported from Canada, the United States, Brazil, Australia, New Zealand and Italy (Wu et al., 2016,2017; Guo et al., 2016; Zhang et al., 2015; Wang et al., 2016; Zhao et al., 2017). There are many complete genome sequences of senecaviruses, which were submitted from 2015 to 2016 (Leme et al., 2017). The SVA

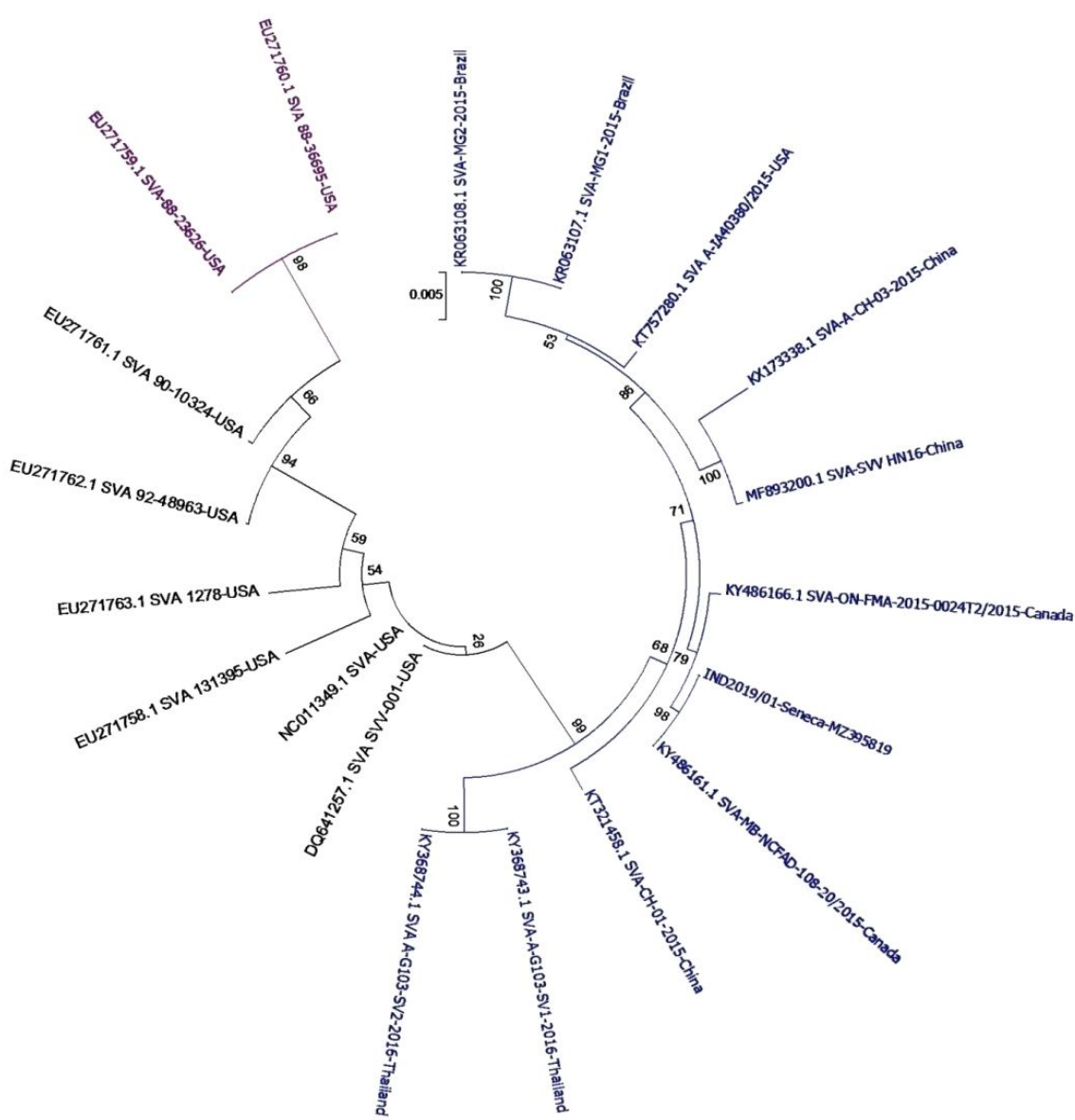

Fig 2: Phylogenetic analysis of Indian Senecavirus A 2019 strain (IND/2019/01/SVA) amino acid sequences with other published sequences present in the GenBank. Neighbour-joining phylogenetic tree was constructed using the $p$ distance method with Bootstrap replicates of 1000 using default parameters. 


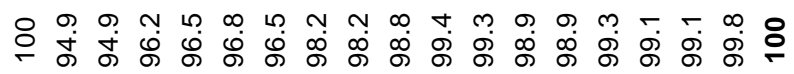

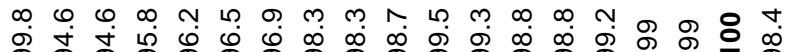

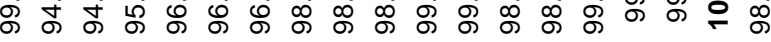
† N N N

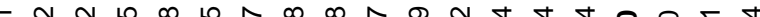

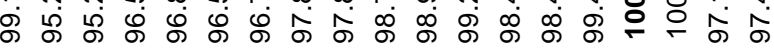

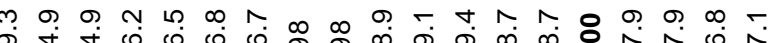

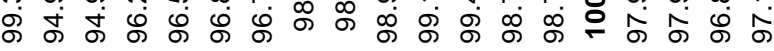
の 它

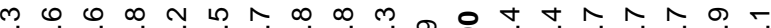

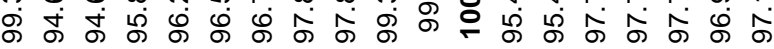

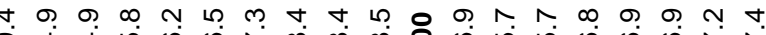
ஓं ர்

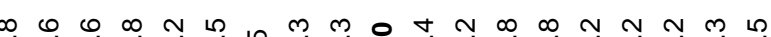
ळ க் க்

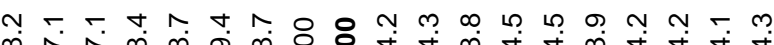

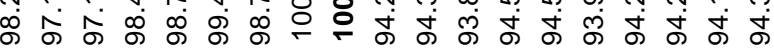
Nָ

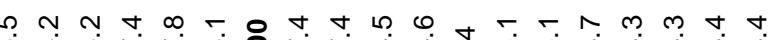

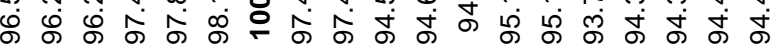
めஆ 岁萬市

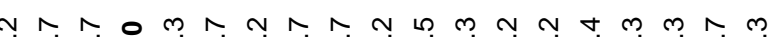

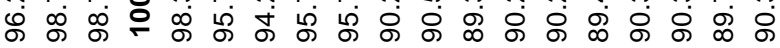

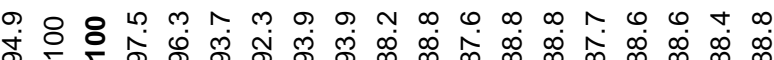

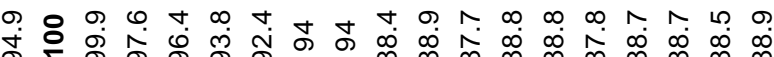

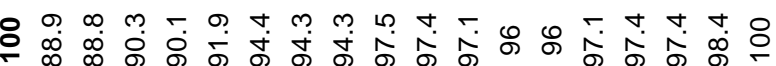

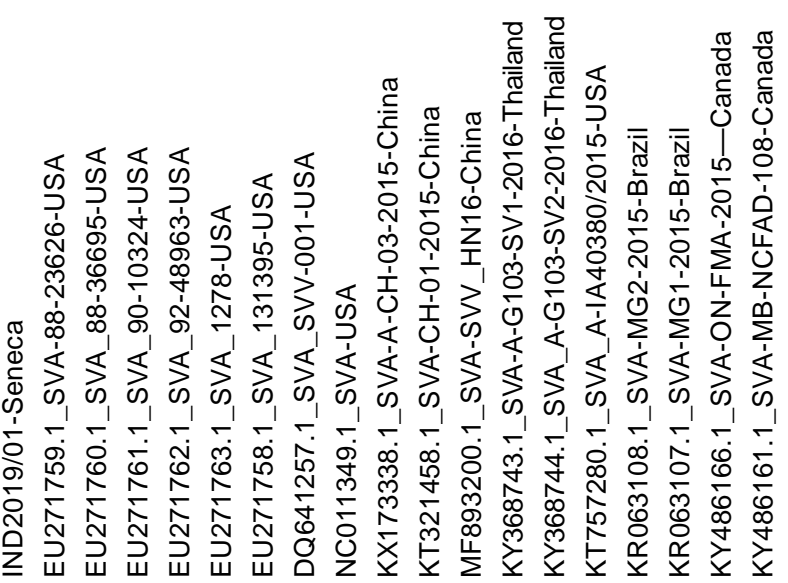


whole genome that was sequenced from the tissue and swab samples from Ohio, USA showed $99 \%$ nt identity to 3 US strains (USA/IA40380/2015, USA/SD41901/2015, USA/ IA46008/2015) and 98\% nt identity to 3 Brazil strains (SVV/ BRA/MG1/2015, SVV/BRA/MG2/2015, SVV/BRA/GO3/ 2015) and $96 \%$ and $94 \%$ nucleotide identity with Canadian strain (11-55910-3) and US strain (SVV-001), respectively (Wang et al., 2016). The two Brazilian strains BRA/UELSVV-A1/15, (accession number: KR075677) and BRA/UELSVV-B2/15, (accession number: KR075678) have, 99.6$100 \%$ nucleotide identity with each other and $87.6 \%$ to $98.5 \%$ with the SVA strains from that of the USA (Leme et al., 2015). In 2018, the SVA has been reported in the outbreak of vesicular disease at a pig farm in Henan, Central China. This strain HeN-1/2018 revealed highest nucleotide identity
(98.4\%) with the 2017 strain from Fujian province (CH-FJ/ 2017) and $98.3 \%$ nucleotide identity with 2017 strains of Henan province (CH-HN/2017 and $\mathrm{CH}-\mathrm{HNSL} / 2017)$ and were clustered with the USA SVA strains in clade III (Wang et al., 2018).

The grouping of senecavirus strains was observed into three temporal clades. Clade I include the prototype senecavirus strains, clade II includes the USA senecavirus strains identified between 1988 and 1997, including SVV001 and clade III contains the contemporary senecavirus strains from Brazil, Canada, China, Thailand and the USA identified including the Indian SVA. The Indian SVA revealed nt/aa identity levels of $100 \% / 100 \%$ to Senecavirus $A$ isolate from Canada from 2015 (Accession Number KY486161) in clade III and minimum nt/aa identity of $88.8 / 94.9 \%$ with that

Table 3: Amino acid changes between Indian Senecavirus A 2019 strain (IND/2019/01/SVA) with other published sequences present in the GenBank.

\begin{tabular}{|c|c|c|c|c|c|c|}
\hline \multirow[b]{2}{*}{ Positions } & \multicolumn{6}{|c|}{ Strains } \\
\hline & $\begin{array}{l}\text { Indian SVA } \\
(\text { IND/2019/01) }\end{array}$ & $\begin{array}{c}\text { USA } \\
\text { (QDZ58658) }\end{array}$ & $\begin{array}{c}\text { Thailand } \\
\text { (ARQ31641) }\end{array}$ & $\begin{array}{c}\text { Canadian } \\
\text { (ARQ19059-69) }\end{array}$ & $\begin{array}{c}\text { Chinese } \\
\text { (AYA73836.1) }\end{array}$ & $\begin{array}{c}\text { Brazilian } \\
\text { (ALD50008) }\end{array}$ \\
\hline 4 & $S$ & $\mathrm{P}$ & $S$ & $S$ & $S$ & $S$ \\
\hline 56 & $\mathrm{R}$ & $\mathrm{K}$ & $\mathrm{R}$ & $\mathrm{R}$ & $\mathrm{R}$ & $\mathrm{K}$ \\
\hline 289 & $\mathrm{~T}$ & $\mathrm{~T}$ & $\mathrm{~T}$ & $A$ & $\mathrm{~T}$ & $\mathrm{~T}$ \\
\hline 426 & $Y$ & $\mathrm{~F}$ & Y & $Y$ & $\mathrm{~F}$ & $\mathrm{~F}$ \\
\hline 493 & V & A & V & V & V & V \\
\hline 504 & $\mathrm{~L}$ & $\mathrm{~V}$ & V & V & V & V \\
\hline 511 & $A$ & $A$ & $\mathrm{~T}$ & $A$ & A & A \\
\hline 575 & $\mathrm{~T}$ & A & $\mathrm{T}$ & $\mathrm{T}$ & $\mathrm{T}$ & A \\
\hline 699 & $\mathrm{P}$ & $\mathrm{P}$ & $P$ & $P$ & $S$ & $P$ \\
\hline 766 & $A$ & A & V & V & V & V \\
\hline 814 & $\mathrm{~F}$ & $\mathrm{~F}$ & $\mathrm{~F}$ & $\mathrm{~F}$ & $S$ & $\mathrm{~F}$ \\
\hline 902 & $G$ & $S$ & $S$ & $G$ & $G$ & $S$ \\
\hline 988 & $\mathrm{~N}$ & $\mathrm{~N}$ & $\mathrm{~N}$ & $\mathrm{~N}$ & $S$ & $\mathrm{~N}$ \\
\hline 1079 & $\mathrm{~K}$ & $\mathrm{~T}$ & $\mathrm{~K}$ & $\mathrm{~K}$ & $\mathrm{~T}$ & $\mathrm{~T}$ \\
\hline 1101 & $\mathrm{~K}$ & $\mathrm{~K}$ & $\mathrm{~K}$ & $\mathrm{R}$ & $\mathrm{K}$ & $\mathrm{K}$ \\
\hline 1148 & $S$ & $\mathrm{G}$ & $S$ & $\mathrm{G}$ & $\mathrm{G}$ & $S$ \\
\hline 1176 & $\mathrm{~T}$ & A & $\mathrm{T}$ & $\mathrm{T}$ & $\mathrm{T}$ & $\mathrm{T}$ \\
\hline 1349 & A & $S$ & A & A & A & A \\
\hline 1411 & $S$ & $G$ & $\mathrm{G}$ & $S$ & $\mathrm{G}$ & $\mathrm{G}$ \\
\hline 1429 & $E$ & D & $E$ & $E$ & $\mathrm{D}$ & $D$ \\
\hline 1438 & I & I & I & I & V & I \\
\hline 1462 & $\mathrm{R}$ & $\mathrm{K}$ & $\mathrm{R}$ & $\mathrm{R}$ & $\mathrm{R}$ & $\mathrm{R}$ \\
\hline 1472 & $E$ & $E$ & D & $E$ & $E$ & $E$ \\
\hline 1476 & $S$ & $S$ & C & $S$ & $S$ & $\mathrm{G}$ \\
\hline 1480 & $\mathrm{~V}$ & $A$ & $A$ & $\mathrm{~V}$ & $A$ & $A$ \\
\hline 1589 & V & $\mathrm{L}$ & V & V & I & V \\
\hline 1594 & $M$ & $M$ & $M$ & $M$ & V & V \\
\hline 1685 & $\mathrm{~L}$ & $M$ & $\mathrm{~L}$ & $\mathrm{~L}$ & $\mathrm{~L}$ & $\mathrm{~L}$ \\
\hline 1721 & $\mathrm{~L}$ & $\mathrm{~L}$ & $M$ & L & L & L \\
\hline 1729 & V & V & I & V & A & V \\
\hline 1850 & $A$ & $A$ & $\mathrm{~V}$ & $A$ & A & A \\
\hline 1851 & $\mathrm{~N}$ & $\mathrm{~N}$ & $\mathrm{~N}$ & $\mathrm{~N}$ & $S$ & $\mathrm{~N}$ \\
\hline 1856 & A & $\mathrm{P}$ & A & A & $\mathrm{P}$ & $\mathrm{P}$ \\
\hline
\end{tabular}


of USA (Accession no. EU271760.1), which falls in clade I. The Indian SVA showed $97.1 \% / 99.3 \% \mathrm{nt} / \mathrm{aa}$ identity with Senecavirus $A$ isolate from USA (Accession Number KT757280.1), 97.5\%/98.8\% nt/aa identity with Senecavirus A isolate from China (Accession Number KX173338), 97.4\%/ 99.1\% nt/aa identity with Senecavirus A isolate from Brazil (Accession Number KR063108.1), all of which are in clade III. The Indian SVA has 100nt difference from that of USA (Accession Number KY486161) and 163 nt difference from that of China (Accession Number KX173339.1). Indian Senecavirus A 2019 strain (IND/2019/01-SVA) groups separately from Chinese SVA (Accession Number MF893200) having 97.1\%/99.3\% nt/aa and from Thailand strain (Accession Number KY368743-44) sharing 96\%/ $98.9 \% \mathrm{nt} / \mathrm{aa}$ identities though all are in the cluster III (Table 2; Fig 2). Cluster II includes historical strains isolated from USA (Accession no. EU271761.1, EU271762.1, EU271763.1 and DQ641257.1).The Indian SVA grouped separately from the first identified SVA strains (SVV-001) from USA (Accession no: DQ641257) sharing 94.3\%/98.2\% nt/aa identity (clade II) and USA senecavirus strains that were identified between 1988 and 1997(Accession no: EU271759-63) sharing 88-90\%/94-96\% nt/aa identity (Clade I). At the polyprotein level, the Indian SVA has revealed $100 \%$ aa identity with Canadian isolate (Accession no. ARQ19059-69), $99 \%$ with different strains from USA (Accession nos. QHF16701.1, QDZ58658.1) and 98-99\% with strains from China (Accession no. AYA73836.1, AWU67440.1). The Indian SVA is showing $97 \%$ similarity at amino acid level with that of Brazil (Accession no. ALD50008) and Thailand strains (Accession no. ARQ31641). The amino acid changes in Indian SVA are depicted in the Table 3. For tracing its origin and detailed molecular epidemiological studies more samples/isolates from the region need to be characterized. Furthermore, due to less reports of SVA it is important that there must be active surveillance for SVA in swine populations and veterinarians must be alert for this disease in India. It is an emerging virus and has been poorly understood related to its transmission, pathogenesis and immunobiology. The investigation of evolutionary dynamics, pathogenesis and epidemiological features of SVA infection, will help in facilitating the development of diagnostics, antiviral strategies for SVA and will offer effective control measures against SVA infection.

\section{CONCLUSION}

NGS study of diarrheic samples revealed the presence of a strain of Seneca Valley virus A (SVA) in pig. The genome sequence of detected SVA shared $88.78 \%$ to $100 \%$ identity with other global isolates that have been reported. This is the first report of presence of SVA in diarrheic samples of pig in India. The SVA infection is the emerging infectious diseases in the swine populations and has significant impact on the productivity and economic potential of the pork industry. In the current situation, there is need for preparedness to develop methods for the early detection and prevention of emerging infectious diseases. The pork production is a globalized industry, the veterinarians and researchers must work in conjunction with producers, consumers and stakeholders for more collaborative and action-oriented approaches for control of these emerging infectious diseases including SVA. However, few diagnostic methods have been established and no commercial vaccine is available until now. Therefore, more attention needs to be paid to SVV and urgent surveillance should be performed to prevent the spread of this virus.

\section{ACKNOWLEDGEMENT}

The authors would like to acknowledge funding support provided by Haryana State Council of Science and Technology (HSCST), grant number 5041/C(G)-ABT-14OA under the project entitled: Detection of porcine viral pathogens using next generation technology (NGS). The authors are thankful to the technical and non teaching staff of the department and also thank LUVAS administration for financial support and smooth running of the NGS facility. Authors also wish to appreciate the work of all the researchers whose work is referenced in the present research.

\section{REFERENCES}

Canning, P., Canon, A., Bates, J.L., Gerardy, K., Linhares, D.C., Piñeyro, P.E., Schwartz, K.J., Yoon, K.J., Rademacher, C.J., Holtkamp, D., Karriker, L. (2016). Neonatal Mortality, Vesicular Lesions and Lameness Associated with Senecavirus A in a U.S. Sow Farm. Transboundary and Emerging Diseases. 63(4): 373-378. https://doi.org/ 10.1111/tbed. 12516.

Carocci, M. and Bakkali-Kassimi, L. (2012). The encephalomyocarditis virus. Virulence. 3(4): 351-367. https://doi.org/10.4161/ viru.20573.

Dall Agnol, A.M., Otonel, R., Leme, R.A., Alfieri, A.A., Alfieri, A.F. (2017). A TaqMan-based qRT-PCR assay for Senecavirus A detection in tissue samples of neonatal piglets. Molecular and Cell Probes. 33: 28-31. https://doi.org/10.1016/ j.mcp.2017.03.002.

Gimenez-Lirola, L.G., Rademacher, C., Linhares, D., Harmon, K., Rotolo, M., Sun, Y., Baum, D. H., Zimmerman, J., Piñeyro, P. (2016). Serological and molecular detection of senecavirus A associated with an outbreak of swine Idiopathic vesicular disease and neonatal mortality. Journal of Clinical Microbiology. 54(8): 2082-2089. https://doi.org/10.1128/ JCM.00710-16.

Guo, B., Piñeyro, P.E., Rademacher, C.J., Zheng, Y., Li, G., Yuan, J., Hoang, H., Gauger, P.C., Madson, D.M., Schwartz, K.J., Canning, P.E., Arruda, B.L., Cooper, V.L., Baum, D.H., Linhares, D.C., Main, R.G., Yoon, K.J. (2016). Novel senecavirus A in swine with vesicular disease, United States, July 2015. Emerging Infectious Diseases. 22(7): 1325-1327. https://doi.org/10.3201/eid2207.151758. 
Hales, L.M., Knowles, N.J., Reddy, P.S., Xu, L., Hay, C., Hallenbeck, P.L. (2008). Complete genome sequence analysis of Seneca Valley virus-001, a novel oncolytic picornavirus. Journal of General Virology. 89(5): 1265-1275. https:// doi.org/10.1099/vir.0.83570-0.

ICTV (2015). Virus Taxonomy: 2015 Release, London.

Joshi, L.R., Mohr, K.A., Clement, T., Hain, K.S., Myers, B., Yaros, J., Nelson, E.A., Christopher-Hennings, J., Gava, D., Schaefer, R., Caron, L., Dee, S., Diel, D.G. (2016). Detection of the emerging picornavirus senecavirus $A$ in pigs, mice and houseflies. Journal of Clinical Microbiology. 54(6): 1536-1545. https://doi.org/10.1128/JCM.03390-15.

Leme, R.A., Alfieri, A.F., Alfieri, A.A. (2017). Update on senecavirus infection in pigs. Viruses. 9(7): 170. https://doi.org/ 10.3390/v9070170.

Leme, R.A., Zotti, E., Alcântara, B.K., Oliveira, M.V., Freitas, L.A., Alfieri, A.F., Alfieri, A.A. (2015). Senecavirus A: An emerging vesicular infection in Brazilian pig herds. Transboundary and Emerging Diseases. 62(6): 603-611. https://doi.org/ 10.1111/tbed. 12430 .

Pasma, T., Davidson, S., Shaw, S.L. (2008). Idiopathic vesicular disease in swine in Manitoba. Canadian Veterinary Journal. 49: 84-85.

Pegu, S.R., Sarma, D.K., Rajkhowa, S., Choudhury, M., Das, J.P., Sarma D. (2017a). Detection of group a rotavirus and histopathological studiesin diarrheic piglets of Kamrup district, Assam. Indian Journal of Animal Research. 51: 742-746.

Pegu, S.R., Sarma, D.K., Rajkhowa, S., Choudhury, M., Sarma D., Das, J.P. (2017b). Molecular detection of porcine circo virus type 2 and porcine parvo virus in pigs having reproductive problems and histopathological studies in the tissue of aborted pig foetuses. Indian Journal of Animal Research. 51: 732-736.

Racaniello, V.R. (2013). In Fields Virology, $6^{\text {th }}$ edn, Vol. 1 (eds Knipe, D.M. and Howley, P.M.), Ch. 16 (Lippincott Williams and Wilkins, 2013).

Rout, M., Subramaniam, S., Mohapatra, J.K., Dash, B.B., Pattnaik, B. (2018). Investigation of foot-and mouth disease outbreak in a pig farm at Kollam district of Kerala, India. Indian Journal of Animal Research. 52: 786-792.
Segalés, J. and Mateu, E. (2012). One world, one health: the threat of emerging and re-emerging viral infections of pigs. Transboundary and Emerging Diseases. 59 Suppl 1, 12. https://doi.org/10.1111/j.1865-1682.2011.01303.x.

Venkataraman, S., Reddy, S. P., Loo, J., Idamakanti, N., Hallenbeck, P.L., Reddy, V.S. (2008). Structure of Seneca Valley Virus001: an oncolytic picornavirus representing a new genus. Structure (London, England: 1993). 16(10): 1555-1561. https://doi.org/10.1016/j.str.2008.07.013.

Wang, L., Prarat, M., Hayes, J., Zhang, Y. (2016). Detection and Genomic Characterization of Senecavirus A, Ohio, USA, 2015. Emerging Infectious Diseases. 22(7): 1321-1323. https://doi.org/10.3201/eid2207.151897.

Wang, Z., Zhang, X., Yan, R., Yang, P., Wu, Y., Yang, D., Bian, C., Zhao, J. (2018). Emergence of a novel recombinant Seneca Valley virus in Central China, 2018. Emerging Microbes Infection. 7(1): 180. https://doi.org/10.1038/ s41426-018-0183-1.

Woolhouse, M.E. (2002). Population biology of emerging and reemerging pathogens. Trends in microbiology. 10(10 Suppl): S3-S7. https://doi.org/10.1016/s0966-842x(02)02428-9.

Wu, Q., Zhao, X., Chen, Y., He, X., Zhang, G., Ma, J. (2016). Complete Genome Sequence of Seneca Valley Virus $\mathrm{CH}$ 01-2015 Identified in China. Genome announcement. 4(1): e01509-15. https://doi.org/10.1128/genome A.01509-15.

Wu, Q., Zhao, X., Bai, Y., Sun, B., Xie, Q., Ma, J. (2017). The First Identification and Complete Genome of Senecavirus A Affecting Pig with Idiopathic Vesicular Disease in China. Transboundary and Emerging Diseases. 64(5): 16331640. https://doi.org/10.1111/tbed.12557.

Zhang, J., Piñeyro, P., Chen, Q., Zheng, Y., Li, G., Rademacher, C., Derscheid, R., Guo, B., Yoon, K. J., Madson, D., Gauger, P., Schwartz, K., Harmon, K., Linhares, D., Main, R. (2015). Full-Length Genome Sequences of Senecavirus A from Recent Idiopathic Vesicular Disease Outbreaks in U.S. Swine. Genome announcement. 3(6): e01270-15. https:/ /doi.org/10.1128/genomeA.01270-15.

Zhao, X., Wu, Q., Bai, Y., Chen, G., Zhou, L., Wu, Z., Li, Y., Zhou, W., Yang, H., Ma, J. (2017). Phylogenetic and genome analysis of seven senecavirus $A$ isolates in China. Transboundary and Emerging Diseases. 64(6): 20752082. https://doi.org/10.1111/tbed.12619. 